\section{Reduce drug waste in the environment}

Environmental contamination by pharmaceuticals is reaching alarming levels (see, for example, Nature 476, 265; 2011) and is set to rise. New partnerships between drug companies, the public-health sector and those who deliver environmental sustainability are urgently needed to tackle the issue.

Low-cost pharmaceuticals are increasingly accessible to the global population, which is predicted to exceed 8 billion by 2050 . Rising drug use is also driven by ageing populations. Widely used preventative medication - such as statins and anti-hypertensives - and cheap generic drugs add to the problem. The UK Office of National Statistics predicts that the country's medicine usage will more than double by 2050 .

Agricultural soils and rivers are contaminated with a range of pharmaceuticals, including antibiotics, antidepressants, analgesics and cancerchemotherapy agents (see go.nature.com/lr2vfy).

The effects are already evident: they include the feminization of fish by residues of the contraceptive pill, and the deaths of millions of vultures on the Indian subcontinent following ingestion of the antiinflammatory drug diclofenac. Antibiotic overuse has led to the emergence of resistant pathogenic bacteria in the wider environment, and not just in medical settings.

Current practices remain unchanged. However, attempts are being made to provoke action. The European Environment Agency has recommended that improvements be made in pharmaceutical-waste management, and that more guidance be provided for the public and for policy-makers. The UK Royal Commission on Environmental Pollution in March highlighted links between demographic change

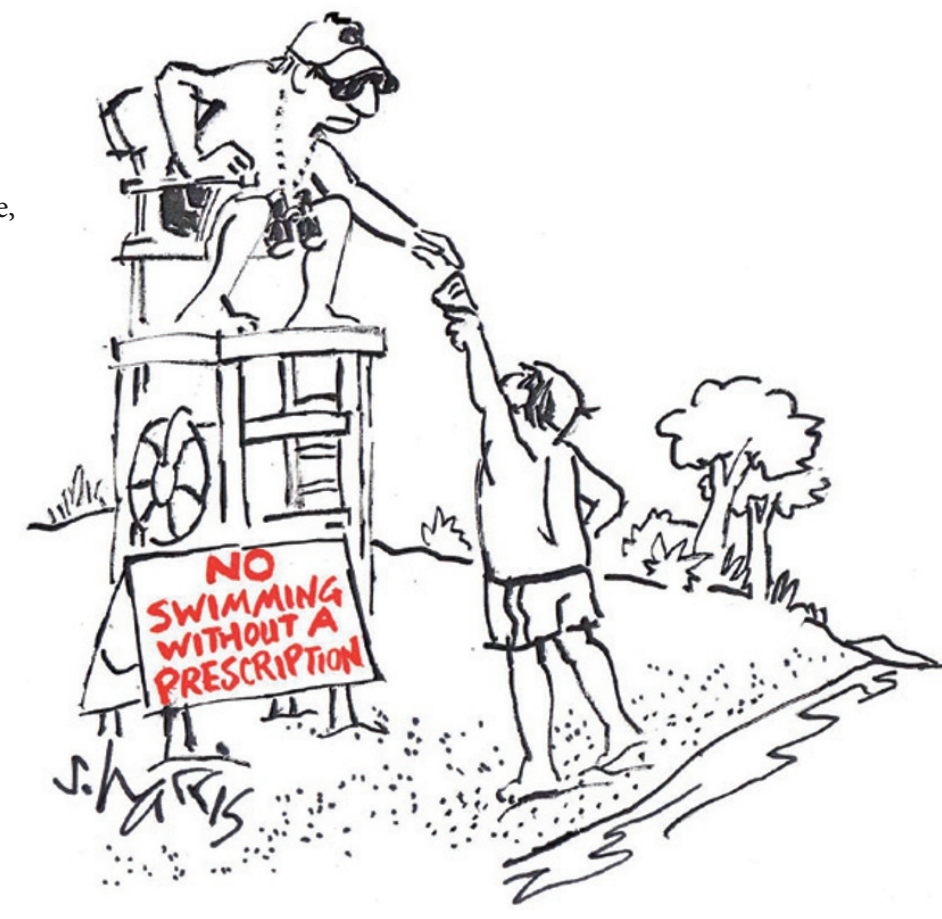

and pharmaceutical releases, and the UK government's Advisory Committee on Hazardous Substances will conduct an investigation.

Michael Depledge European Centre for Environment and Human Health, University of Exeter, UK. michael.depledge@pms.ac.uk

\section{Bridging the gender gap in UK science}

Sally Davies, the Chief Medical Officer for England, has broken new ground for gender equality in the sciences in a letter to the UK Medical Schools Council on 29 July. She will make it a requirement for academic departments applying for funding from the English National Institute for Health Research to hold the silver award of the Athena SWAN (for 'scientific women's academic network') Charter. We urge other funding bodies, including the UK research councils and the Royal Society, to follow suit.

The charter recognizes good employment practice for women in UK science, engineering and departments and one gold department (the University of York's chemistry department). The next deadline for submissions is 30 November. Athene Donald University of Cambridge, UK.

Paul H. Harvey, Angela R.

McLean University of Oxford, UK. paul.harvey@zoo.ox.ac.uk Competing interests declared. See http://dx.doi. org/10.1038/478036b.

\section{Cloning advance calls for careful regulation}

In this issue, Scott Noggle and colleagues describe the generation of human pluripotent stem cells using somatic cells and human oocytes, a technique that bypasses ethical concerns about exploiting fertilized embryos for their medical potential (Nature 478, 70-75; 2011).

The cell lines were produced at the New York Stem Cell Foundation using private funds, in accordance with the Empire State Stem Cell Board's policy of compensating egg providers for research. Unfortunately, many scientists will not have access to these cells, owing to regulations that prevent the publicly funded use of stem cells derived from research embryos and compensated egg donors. These policies - including those in place in California and at the US National Institutes of Health - are well intentioned, but possibly misguided.

To generate their stem-cell lines, Noggle et al. use human oocytes in a new twist to the cloning technique known as somatic-cell nuclear transfer (SCNT). Societal fears about reproductive cloning should not force knee-jerk legislation to ban all forms of human SCNT. The use of this technique in research has a clearly regulated goal: to provide patient-specific stemcell lines to help treat human disease, just like the almost universally supported research involving induced pluripotent 